\title{
El Seminario Conciliar de Mallorca durante el Setecientos. Entre el flore- cimiento y la decadencia
}

\author{
Francisco José García Pérez ${ }^{1}$
}

Recibido: 2 de noviembre de 2016 / Aceptado: 13 de junio de 2017

Resumen. Este artículo pretende estudiar la fundación y evolución del Seminario de Mallorca durante el siglo XVIII. Partiendo de sus inicios, se observarán las difíciles condiciones que hubo para conseguir un seminario conciliar, así como los obstáculos que continuamente se sucedían. Sólo durante la segunda mitad del Setecientos, se pudieron implantar algunas de las grandes reformas de Carlos III, que pretendían elevar la instrucción del clero y, por lo tanto, mejorar la situación de los seminarios españoles, incluido el de San Pedro de Mallorca.

Palabras clave: seminario; Mallorca; obispo; educación.

[en] The Tridentine Seminar of Majorca during the XVIIIth century. Between the Florewing and the Decline

\begin{abstract}
This article pursues to study the foundation and evolution of Seminar of Majorca during the XVIIIth Century. Starting its beginnings, there will be observed the difficult conditions that existed to obtain a Tridentine Seminar, as well as the obstacles that continuously happened. Only during the second half of XVIIIth Century, the big reforms of Charles III was implanted, trying to raise the instruction of clergy and to improve the situation of Spanish Seminars, including Saint Peter of Majorca.

Keywords: Seminar; Majorca; Bishop; Education.
\end{abstract}

Sumario. 1. Introducción: balance y nuevas perspectivas. 2. La fundación del Seminario Conciliar de San Pedro. 3. Los difíciles inicios del seminario y las primeras reformas. 4. El gran proyecto del obispo Juan Díaz de la Guerra. 5. Conclusiones.

Cómo citar: García Pérez, F.J. (2017) El Seminario Conciliar de Mallorca durante el Setecientos. Entre el florecimiento y la decadencia, en Cuadernos de Historia Moderna 42.1, 221-238.

\section{Introducción: balance y nuevas perspectivas}

E1 Seminario de Mallorca ha interesado más bien poco a la historiografía mallorquina reciente. A día de hoy no son muchos los trabajos con que contamos y, al mismo tiempo, estos no terminan de ofrecer una visión ecuánime de la fundación y evolu- 
ción de aquel edificio ligado íntimamente a la formación del clero isleño. En 1900, el canónigo Mateu Capllonch elaboró un pequeño estudio sobre el Seminario que abarcaba desde su fundación hasta los últimos años del siglo XIX ${ }^{2}$. Se trataba de una pequeña síntesis que abría el camino a nuevas investigaciones, aunque finalmente la irrupción de otras temáticas hizo que los entonces pocos historiadores de la Iglesia de Mallorca olvidasen durante mucho tiempo el estudio del Seminario. De hecho, el acceso a los fondos documentales, especialmente en el Archivo Diocesano de Mallorca (ADM,) era francamente difícil.

La contribución más importante hasta el momento ha sido la tesis doctoral presentada en 1986 por el historiador Joan Rosselló Lliteras, que ofrecía un análisis mucho más profundo del viejo seminario ${ }^{3}$. De hecho, parece ser que su tesis doctoral alejó todavía más a muchos historiadores, creyendo quizás que dicha temática estaba ya suficientemente estudiada. Pero lo cierto es que, a día de hoy, se hace necesaria una revisión historiográfica urgente sobre el Seminario. En su tesis doctoral, Rosselló Lliteras se basó únicamente en fuentes documentales del Archivo Diocesano de Mallorca (ADM), ofreciendo un discurso fragmentario y, en ocasiones, más interesado en exaltar dicha institución. Pero lo cierto es que el asunto del Seminario no solo preocupó a los obispos del momento, sino que se tradujo una cuestión en boga de las principales instituciones de poder de la Mallorca del siglo XVIII. Por lo tanto, las referencias documentales al Seminario no solo se localizan en dicho archivo. Precisamente, este artículo pretende ofrecer una revisión historiográfica a partir del hallazgo de nueva documentación que el historiador Rosselló eludió en sus trabajos, y que ofrece un análisis novedoso sobre el Seminario de Mallorca.

Actualmente no es posible acceder a los documentos que Rosselló Lliteras consultó para su tesis doctoral, ubicados en el ADM, ya que estos se encuentran descatalogados. Ahora bien, como se viene diciendo, lo realmente interesante en este artículo es el análisis de una documentación relacionada con el Seminario conciliar de Mallorca, y repartida en otros muchos archivos históricos que Rosselló Lliteras pasó por alto. De sumo interés son las actas del Archivo Capitular de Mallorca (ACM) y también las del Archivo Municipal de Palma (APM), primero porque el Cabildo fue una de las instituciones mayormente involucradas en la fundación y evolución del Seminario, por detrás del obispo, y segundo porque los regidores del Ayuntamiento jamás fueron ajenos del todo a la evolución de dicha sede. Asimismo, otros archivos conservan documentos de sumo interés, como los fondos que todavía se conservan del archivo de San Francisco, en la Biblioteca Bartomeu March (BBM), o los manuscritos de la Biblioteca Pública de Mallorca (BPM). Asimismo, el Archivo del Reino de Mallorca (ARM), sin lugar a dudas uno de los más importantes, conserva documentos ciertamente interesantes que hacen referencia al Seminario de San Pedro, y que deben ser tenidos en cuenta.

Vid. Rotger Capllonch, M.: El Seminario Conciliar de San Pedro. Estudio histórico sobre la enseñanza eclesiástica en Mallorca, Palma, Tipo-litografía, 1900.

3 Vid. Rosselló Lliteras, J: Formación literaria del clero de Mallorca: el Seminario de San Pedro y sus antecedentes históricos, Palma, Tesis doctoral inédita, 1988. 


\section{La fundación del Seminario Conciliar de San Pedro}

Desde los días del Concilio de Trento, el clero parroquial había experimentado una serie de transformaciones internas, consecuencia de las ansias de reforma y persecución de los viejos vicios que arrastraba la Iglesia medieval ${ }^{4}$. En Mallorca, al igual que en el resto de diócesis hispánicas, se dejaron ver importantes cambios. En primer lugar, los sínodos del siglo XVII estipularon distintas regulaciones que prescribían los deberes y vestimenta reservados a cada estrato dentro de la jerarquía ${ }^{5}$. De igual modo, los curas párrocos debieron someterse a una forzosa permanencia en su respectiva parroquia, y en cuanto aquellos que optasen a un beneficio curado, "independientemente de quien posea el derecho de presentación, se realiza por concurso oposición en todos los meses del año"6. Los requisitos de acceso estaban claramente estipulados y el candidato debía presentar la documentación necesaria si quería optar al derecho de examen: probar la pureza de sangre, tener la edad mínima reglamentaria y estar libre de todo impedimento canónico, además de disponer de inclinación al estado eclesiástico; cosa, en palabras de Barrio Gozalo, difícil de detectar ${ }^{7}$. Ahora bien, la formación era también un asunto importante, aunque es cierto que después de Trento aún no existían unas disposiciones del todo uniformes.

Ya durante el siglo XVII, distintos obispos dieron la voz de alarma tras constatar, a través de las visitas pastorales, las grandes lagunas educativas existentes, hasta el punto de que muchos sacerdotes se veían incapaces de enseñar el catecismo a los niños $^{8}$. Si bien es cierto que, para recibir las órdenes menores, únicamente se exigía una buena instrucción en la doctrina cristiana y conocer medianamente el latín", para obtener las órdenes mayores, y especialmente el presbiterado, se requerían conocimientos de filosofía y teología que debían acreditarse mediante los exámenes oposición antes mencionados ${ }^{10}$. Por tanto, era necesaria una instrucción profunda si se ansiaba llegar a ese escalafón. Y aquí aparece la necesidad tridentina de dotar a las diócesis de seminarios, "para la educación y enseñanza del clero, y hacer así firme la reforma de la Iglesia desde sus cimientos"11. Sin embargo, en lo que a Mallorca se refiere, durante los siglos XVI y XVII, la isla vivió siempre privada de un seminario

4 Vid. Vidal Estelrich, J. A.: "El clero de Mallorca con cura de almas al introducirse la reforma tridentina", Bolletí de la Societat Arqueolòica Lul·liana, 41 (1985), pp. 269-278.

5 La implantación de reformas episcopales sobre el clero ya era una realidad años antes de la implantación del Concilio de Trento. De hecho, distintos obispos se esforzaron por extirpar distintos abusos y desmanes existentes en sus respectivas diócesis, si bien es cierto que, muchas veces, no era un objetivo muy fácil de conseguir. Xamena, P. y Riera, F.: Història de l'Església de Mallorca, Palma, Moll, 1986, p. 188.

6 Barrio Gozalo, M.: El sistema beneficial de la Iglesia española en el Antiguo Régimen (1475-1834), Alicante, Universidad de Alicante, p. 121.

7 Cada vez se hacía más importante para los obispos y los sínodos diocesanos esclarecer las auténticas razones por las que el aspirante quería entrar a formar parte del estamento eclesiástico. Ciertamente, se daban casos sobrados de personas que buscaban eximirse de la jurisdicción civil, para pasar a depender de la jurisdicción eclesiástica. Asimismo, las ventajas que reportaba un beneficio eclesiástico eran tenidas en cuenta por muchos aspirantes que, más allá de su supuesta vocación pastoral, buscaban una vida mejor. Así pues, se dieron informes basados en interrogatorios, pruebas de juramento y otras estrategias. BARRIo GozALO, M.: El clero en la España moderna, Córdoba, CSIC, p. 147.

8 Amengual i Batle, J.: Llengua i catecisme: entre la pastoral i la política, 1576-1962, Palma, Institut d'Estudis Baleàrics, 2002, p. 75.

9 Barrio Gozalo, op. cit. (nota 6), p. 145.

10 Rosselló Lliteras, J.: "Els confessors i directors espirituals dels seminaristes de Mallorca (segles XVIIIXIX)", Randa, Homenatge a Miquel Batllori/3, 50 (2003), p. 89.

11 Mateo Ripoll, V.: "Las disposiciones conciliares en torno a la enseñanza del clero", Orígenes del Seminario de Orihuela, 1742-1790, Murcia, Caja de Ahorros del Mediterráneo-Obispado Orihuela, 1992, p. 24. 
conciliar a imagen de las disposiciones establecidas en el Concilio de Trento ${ }^{12}$.

Los problemas para su fundación no fueron pocos. En primer lugar, los canónigos de la Catedral no veían con buenos ojos ceder parte de los réditos que les reportaban sus prebendas para la construcción del edificio. En segundo lugar, existían ya centros destinados a la formación del clero, pero que en muchos sentidos no terminaban de cumplir con los objetivos que había promovido Trento. Y finalmente, muchas veces los obispos estaban más interesados en otros ámbitos de la Diócesis, considerando que las infraestructuras destinadas a la formación del clero eran ya suficientes.

Como se viene diciendo, durante el Seiscientos, existían varios centros destinados a esta tarea que venían a suplir la ausencia de un Seminario. Primeramente, las órdenes religiosas disponían de escuelas en sus propios conventos. Los dominicos contaban con un aula de Gramática en Santo Domingo. Fuertemente imbuidos en las doctrinas de Santo Tomás, los padres predicadores habían conseguido fortalecer el estudio del tomismo desde hacía siglos ${ }^{13}$. Asimismo, los franciscanos enseñaban las doctrinas de Escoto en su convento ${ }^{14}$. Y finalmente, el colegio de Montesión, fundado por la Compañía de Jesús, se convirtió también en uno de los centros educativos más prominentes durante el siglo XVII ${ }^{15}$. Especialmente tras la gracia regia que Felipe IV concedió a los jesuitas en 1626 para que pudiesen colacionar grados de Artes y Teología ${ }^{16}$.

Asimismo, a finales de esa centuria, los Jurados de la Ciudad y Reino de Mallorca, ayudados por el obispo y el Cabildo de la Catedral, consiguieron transformar el antiguo Estudio General en una Universidad. La llamada Universidad Luliana y Literaria de Mallorca, en comunión con las órdenes religiosas mencionadas anteriormente, privilegió por encima de otras doctrinas, las del beato mallorquín Ramón Llull ${ }^{17}$. Aunque allí se impartían las cuatro grandes doctrinas, el lulismo siempre tuvo un papel muy relevante en la vida universitaria.

Además de lo anterior, existía otra institución ligada también el clero y a su formación, que iba a tener un enorme peso en el futuro Seminario de San Pedro. En 1633 se vivió en Mallorca un movimiento pedagógico vigorizador, promovido por distintos obispos y en conexión con las directrices establecidas por Trento. Así nació el colegio de Nuestra Señora de la Sapiencia ${ }^{18}$. Fundada en 1633 por un canónigo de la Catedral, Bartolomé Llull, la Sapiencia se caracterizaba por ser un "colegio de carácter puramente clerical; porque los colegiales deben sinceramente aspirar al

12 Esta situación no fue en absoluto extraordinaria de Mallorca. Todo lo contrario, la implantación de los decretos tridentinos dedicados a una mejora en la enseñanza del clero, y, por lo tanto, la erección de seminarios conciliares, fue muy complicada. De hecho, muchas diócesis del sur de Europa todavía a inicios del siglo XVIII carecían de seminarios que garantizasen una mejor formación eclesiástica. Sobre los inicios de la implantación de seminarios conciliares, especialmente en Italia, véase SANGALLI, M: "La formación del clero católico en la edad moderna. De Roma, a Italia, a Europa”, Manuscrits, 25 (2007), pp. 101-128.

13 Ramis Barceló, R.: "La enseñanza en el convento de Santo Domingo de Palma de Mallorca (s. XVIII)", en Alabrús, R. M. (ed.): La vida cotidiana y la sociabilidad de los dominicos, Barcelona, Arpegio, 2013, p. 175.

14 Cassanyes Roig, A. y Ramis Barceló, R.: "Los grados en Teología escotista en la Universidad Luliana y Literaria de Mallorca (1692-1823)", Archivo Ibero-Americano, 277-278 (2014), p. 9.

15 Ferrer Flórez, M.: "Historia de los colegios de la Compañía de Jesús en Baleares", Bolletí de la Societat Arqueològica Lul·liana, 64 (2008), p. 135.

16 Véase Ramis Barceló, R.: "La Historia del Colegio de Montesión de Palma de Mallorca (1561-2011)", Archivum Historicum Societatis Iesu, 163 (2013), pp. 267-281.

17 Ramis Barceló, R.: "Un esbozo cartográfico del lulismo universitario y escolar en los reinos hispánicos", Cuadernos del Instituto Antonio de Nebrija, 15/1 (2012), p. 92.

18 Véase Trias Mercant, S.: Filosofía y Sociedad. Hacia una ecología del lulismo de la Ilustración, Palma, Instituto de Estudios Baleáricos, 1973, pp. 44 y ss. 
sacerdocio"19. Allí residían doce jóvenes que contaban con una beca que cubría no solo su estancia en el colegio, sino también su instrucción académica en la Universidad. De modo que la Sapiencia, un colegio en el que no se impartían estudios propios, funcionaba de modo muy parecido a como lo iba a hacer el futuro Seminario de San Pedro.

Todo lo anterior, sin embargo, era insuficiente para la correcta formación del clero mallorquín. De hecho, parece ser que, a inicios del siglo XVIII, la mayoría de diócesis españolas -incluida la de Mallorca- contaban con unos sacerdotes mal preparados y muchas veces desinteresados con sus deberes parroquiales ${ }^{20}$. A inicios de la centuria, todavía había muchas diócesis que no tenían un seminario propio ${ }^{21}$. Y otras veces, los ya existentes se mostraban precarios e ineficaces para la correcta formación de los futuros sacerdotes ${ }^{22}$. En Mallorca, los obispos del Seiscientos se sucedieron de unos a otros la siempre pendiente cuestión del seminario. Unos denunciaban la imperante necesidad de su fundación, pero no terminaban de contar con el coraje suficiente para emprender tan imponente tarea. Y otros, sin embargo, relegaban dicha cuestión para un momento más apropiado.

Por ejemplo, cuando en 1681 el obispo Bernardo Cotoner (1671-1684) se tomó como un reto personal dotar a su Diócesis de un seminario en condiciones, los obstáculos fueron demasiados para conseguirlo ${ }^{23}$. Las disputas entre el prelado y los canónigos de la Catedral se hicieron tan evidentes y notables, que se movieron voces fuera de la órbita religiosa. De hecho, los Jurados empezaron a presionar a la jerarquía eclesiástica para que promoviese el proyecto de erección de un seminario conciliar ${ }^{24}$. Finalmente, fue el obispo Pedro de Alagón (1684-1701) quien se decidió a poner la primera piedra. Superando los impedimentos que ponía el siempre receloso Cabildo catedralicio, fundó el Seminario de San Pedro de Mallorca el 29 de junio de $1700^{25}$.

Una vez elegidos los diputados, dieron inicio las obras del que iba a ser el nuevo edificio elegido ${ }^{26}$. Como Alagón tenía cierta prisa por concluir con el plan, utilizó un viejo caserón que antaño había sido el improvisado convento de las capuchinas de $\mathrm{Palma}^{27}$. Su ambición a la hora de concluir un proyecto que había ido postergándose durante más de un siglo, se evidencia primeramente por las improvisaciones a las que se vio sometido, así como a las enormes energías que puso. No en vano, el prela-

19 Alcover Sureda, M.: Origen, naturaleza y valor pedagógico de un colegio luliano (de la revista Razón y Fe), Palma, Apóstol y Civilizador, 1985, p. 10.

20 Barrio Gozalo, M.: "El clero bajo sospecha a principios del siglo XVIII. El Informe de Macanaz y la respuesta de los obispos", Investigaciones Históricas, 22 (2002), p. 51.

21 Mas Galván, C.: "Tres seminarios españoles del Setecientos: Reformismo, Ilustración y Liberalismo", Cuadernos de Historia Moderna. Anejos, 3 (2004), p. 166.

22 Por poner un ejemplo extensible a gran número de seminarios, el de San Bartolomé, en Cádiz, no contaba a inicios del siglo XVIII con estudios de Gramática, materia que era impartida por la Compañía de Jesús fuera de sus paredes. Además, estaba considerado como un centro poco prestigioso y padecía problemas económicos severos. Morgado García, A.: "La reforma del Seminario de San Bartolomé (Cádiz) en el siglo XVIII", Anales de la Universidad de Cádiz, 5-6 (1986), p. 280.

23 Amengual i Batle, J.: Història de l'Església a Mallorca. Del Barroc a la Illustració (1563-1800), Palma, Lleonard Muntaner, 2002, p. 162.

24 Parece ser que, en 1691, los Jurados elevaron una queja a Carlos II, y expuesta en el sínodo de 1691, en la que denunciaban la necesidad de fundar un nuevo seminario conciliar en Palma. Terrassa, G.: Anales del Reino de Mallorca. Desde 1659 hasta el año de 1699, Palma, 1840, p. 179-180.

25 Campaner i Fuertes, A.: Cronicón mayoricense, Palma, Ajuntament de Palma, 1984, p. 540.

26 Rotger CAPllonch, op. cit. (nota 2), p. 22.

27 Rosselló Lliteras, op. cit. (nota 3), p. 389. 
do diseñó las constituciones del Seminario, y aprovechaba algunos momentos libres para visitar personalmente a los nuevos seminaristas ${ }^{28}$.

En sus inicios, el Seminario de San Pedro daba cabida a doce seminaristas, aunque las previsiones del proyecto auguraban que se pudiese aumentar esa cifra a un número de veinticuatro cuando el edificio estuviese definitivamente terminado ${ }^{29}$. Asimismo, solo contaba con un número limitado de becas para dotar, mientras que el resto de seminaristas tenían que pagar su estancia de su propio bolsillo -de ahí que se les llamara porcionistas, porque pagaban su alojamiento o porción $-^{30}$. Por otro lado, y en consonancia con las disposiciones tridentinas, la edad de ingreso era bastante prematura, alrededor de los doce años de edad. De ese modo, se pretendía que los nuevos seminaristas adquiriesen una profunda instrucción religiosa. Y en lo que se refiere a la dirección del Seminario, contaba con un rector, que quedaba directamente bajo las órdenes del prelado diocesano y, por lo tanto, debía informarle mensualmente de todo lo relacionado con la evolución del Seminario. Ayudado en todo momento por un vicerrector, el rector no solo administraba la economía interior del edificio, sino que también "los dos hacen diariamente paso y repaso de la lección de los seminaristas, a cada uno de sus respectivos libros y materias: que presiden las conferencias, lecciones de oposición y otros continuos ejercicios que tienen" ${ }^{31}$.

En cuanto a la instrucción de los seminaristas, el nuevo Seminario no contaba con un cuerpo de maestros propio, sino que funcionaba como una residencia, de forma parecida a como lo hacía la Sapiencia. De hecho, las autoridades del Seminario observaron con recelo la continuidad de aquel colegio, ya que en la práctica se trataba de otra residencia que privaba al edificio de nuevos aspirantes al sacerdo$\mathrm{cio}^{32}$. Por lo tanto, los seminaristas se veían obligados a formarse fuera, utilizando las infraestructuras académicas que todavía pervivían en Mallorca desde los siglos anteriores. Según las Constituciones del Seminario, las Humanidades las cursaban en Montesión 33 “y las Artes, Teología, Moral y Escritura Sagrada en la Universidad, reservando a nos [el obispo] la elección de la doctrina que han de profesar en las escuelas menores" ${ }^{\prime 34}$.

Esto tiene cierta importancia, ya que los seminaristas estaban en contacto directo con otros estudiantes, y por lo tanto se veían también sometidos a las disputas doctrinales y teológicas que imperaban en la Universidad luliana. No en vano, las tensiones sociales y religiosas que se vivieron en Mallorca no fueron ajenas al recién fundado Seminario de San Pedro.

28 Llinas, R.: Sermón en las exequias del Ilmo. Señor D. Pedro de Alagón, arzobispo obispo de Mallorca del Consejo de su Majestad, Palma, imp. Miguel Capó, 1701, p. 36.

29 Archivo Capitular de Mallorca (ACM), Actas Capitulares, 1643, fol. 178.

30 Rosselló Lliteras, J.: “Don Juan Díaz de la Guerra y el Seminario de Mallorca”, Estudios Lulianos, 28 (1988), p. 212.

31 Biblioteca Bartomeu March (BBM), Fondo del Convento de San Francisco, leg. 6, s/f.

32 Una de las grandes diferencias que había entre el colegio de la Sapiencia y el Seminario de San Pedro era el sistema de gobierno de ambas comunidades. Ambos edificios contaban con un rector que vigilaba los movimientos de sus integrantes, ahora bien, mientras el Seminario estaba subyugado en última instancia a la autoridad del obispo, que gozaba de un fuerte intervencionismo, los colegiales de la Sapiencia funcionaban con mucha autonomía. Si bien los Jurados de Mallorca y los obispos eran sus patronos, los colegiales disponían de un autogobierno que se hizo muchas veces incómodo para unos prelados cada vez más celosos de su poder y prerrogativas. Ramis BARCELó, R.: "Los colegiales del pontificio colegio de la Sapiencia de Mallorca durante el siglo XVIII", Obradoiro de Historia Moderna, 23 (2014), p. 250.

33 Amengual i Batle, op. cit. (nota 23, 2002), p. 165.

34 Archivo del Reino de Mallorca (ARM), Audiencia, AA 0756/6, fol. 17. 


\section{Los difíciles inicios del seminario y las primeras reformas}

Los nuevos seminaristas se vieron afectados desde un principio por las discordias que imperaban en el mundo académico mallorquín. Dentro de la Universidad luliana, se vivía día a día una confrontación velada entre las distintas doctrinas que allí se enseñaban, especialmente entre el tomismo y el lulismo ${ }^{35}$. Mientras los profesores lulistas hacían lo imposible por privilegiar las doctrinas de Ramón Llull, hasta el punto de convertir la Universidad en un auténtico bastión capaz de proteger el legado del que llamaban el Doctor Iluminado, los profesores de tomismo, especialmente los dominicos, batallaban sin descanso para acabar con todo rastro de lulismo ${ }^{36}$. De modo que los pasillos universitarios se estaban convirtiendo en un enjambre de disputas entre miembros del profesorado, peleas y abusos entre los propios estudiantes -incluidos los seminaristas- en función de la doctrina que aprendían, y lo que es peor, violentos atentados que alteraban el día a día de las clases ${ }^{37}$.

Este contacto diario de los seminaristas con el resto de estudiantes de la Universidad también les afectó a ellos. Y uno de los elementos que mayor influencia pudo tener, fue la devoción al ya mencionado Ramón Llull. En efecto, no solo se enseñaban sus doctrinas en la Universidad, sino que, desde finales de la Edad Media, existía un culto religioso dedicado a su persona, y con una fuerte incidencia en la sociedad mallorquina ${ }^{38}$. De hecho, aunque en el Seminario cada uno de sus miembros tenía plena libertad para elegir la opinión que quisiese estudiar, generaciones de seminaristas sentían una especial devoción por el Doctor Iluminado. Hasta tal punto era así, que muchos de ellos contaban con pequeñas tallas de barro que colocaban en sus habitaciones ${ }^{39}$. Y, además, desde un principio pervivía la tradición de que "se ha rezado siempre un padrenuestro en comunidad al B. Lulio"40. Por lo tanto, la disparidad de opiniones también se dejó notar en el Seminario, aunque en un principio no fue evidente.

Por el momento, el Seminario iniciaba sus pasos con algunas dificultades. Su fundación coincidía con el estallido de la Guerra de Sucesión. Con la isla mayoritariamente dividida en favor del candidato Carlos de Austria, el obispo que llegó tras la muerte de Alagón, Francisco de la Portilla (1701-1710), un declarado filipista, se vio obligado a dejar a un lado el nuevo seminario y preocuparse por su delicada situación. En 1708, el obispo fue forzado a marcharse de Mallorca por sus simpatías

RAmis BARCELó, R.: "Sobre la denominación histórica de la Universidad de Mallorca: problemas institucionales e ideológicos en torno al lulismo", Cuadernos del Instituto Antonio de Nebrija, 13/2 (2010), p. 251.

36 Ramis Barceló, R.: "Las cátedras tomistas de la Universidad Luliana y Literaria de Mallorca (1692-1824)", Archivum Fratrum Praedicatorum, 83 (2013), p. 351.

37 Vid. Cassanyes Roig, A. y Ramis Barceló, R.: "El atentado antiluliano de 1699 en el marco ideológico de la Universidad de Mallorca”, Memòries de la Reial Acadèmia Mallorquina d'Estudis Genealògics, Heràldics $i$ Històrics, 22 (2012), pp. 141-166.

38 Desde la muerte de Ramón Llull (1229-1315), famoso filósofo y pensador medieval de origen mallorquín, se gestó en Mallorca una potente devoción de raigambre local que fue expandiéndose a lo largo de la Edad Moderna. Con los restos mortales del que llamaban el Doctor Iluminado reposando en la iglesia de San Francisco, dicha veneración contaba con un potente programa ceremonial que incluía dos fiestas anuales oficiales, imágenes del Beato en la mayoría de iglesias y conventos, santuarios dedicados por entero a su devoción, y la protección de la élite civil y religiosa de la isla. Asimismo, desde tiempos inmemoriales se consideraba a Ramón Llull un intercesor celestial para la llegada de las lluvias, y año tras año, se le dedicaban rogativas. Vid. Ferrer FLórez, L.: "Culte a Ramon Llul. Discòrdies i controvèrsies", Studia Lulliana, 41 (2001), pp. 66 y ss.

39 ARM, Lul·lisme, 45, s/f.

40 BBM, Fondo del convento de San Francisco, leg. 6, s/f. 
hacia Felipe $\mathrm{V}^{41}$, y el poder religioso quedó en manos del Cabildo catedralicio, que lo administraba a través de un vicario general sede vacante. Durante aquellos años, la inestabilidad que respiraba el estamento eclesiástico se dejó notar también en el Seminario. El rector del mismo dio la voz de alarma por la precariedad que estaba viviendo, porque "les faltan los medios de su manutención, porque todos se resisten de contribuir las porciones que respectivamente les toca según el último repartimiento"42.

Aunque es cierto que en 1710 se consiguió aumentar el número de seminaristas a quince, no se hizo mediante una dotación de becas, sino que ingresaron nuevos seminaristas que pagaban su estancia en el Seminario de su propio bolsillo ${ }^{43}$. Ciertamente, fueron años difíciles, en los que el rector de aquel momento observaba impotente cómo la gran obra de Alagón parecía hundirse lentamente. Las esperanzas de aquel nuevo Seminario se resquebrajaban mientras el vicario sede vacante se hallaba más preocupado por estabilizar las discordias que se reproducían, y el Cabildo catedralicio se desentendía de un proyecto que él mismo había consentido en apoyar a regañadientes.

En 1711 el obispo Portilla murió sin haber visto cumplido su deseo de volver a la isla, y el archiduque Carlos de Austria nombró a otro más digno de su confianza: Atanasio de Estérripa y Tranajáuregui (1711-1721) ${ }^{44}$. Este nuevo prelado llegaba a la Diócesis en mitad de la inestabilidad social y religiosa que seguía generando la situación de guerra. Pero no por ello, dejó de lado su interés por aquel pequeño Seminario. En octubre de 1714, Estérripa convocó un examen para la provisión de dos becas vacantes, exigiendo a los aspirantes que "además de ser estudiantes pobres y naturales de nuestra diócesis, que sean de legítimo matrimonio, de sangre limpia y de buenas costumbres, y que tengan por lo menos doce años"45. Asimismo, hizo un esfuerzo imperioso por evitar que el Seminario terminase agonizando; y para tal fin, compró algunas casas adyacentes al edificio, que costeó a sus expensas. Y, además, aplicó una porción de los réditos de las parroquias de Montuïri y Campanet, con la intención de elevar los ingresos del Seminario y poder así continuar con su ampliación ${ }^{46}$.

Acabada ya la guerra en 1715, las décadas siguientes parecieron prolongar esta tónica de frustrados avances para conseguir erigir un Seminario acorde a los intereses tridentinos. En primer lugar, el Cabildo se desentendió nuevamente de sus deberes para con el Seminario. Los canónigos de la Catedral evitaron apoyar económicamente a los prelados diocesanos, ya que eso, como se viene diciendo, suponía privarles de parte de los beneficios económicos de sus prebendas. De hecho, estos aprovechaban los períodos de sede vacante para frenar los avances en el edificio, especialmente si consideraban que les perjudicaban ${ }^{47}$.

En segundo lugar, los obispos de este momento tuvieron serios problemas para lanzarse a una reforma integral del Seminario; primeramente, por los problemas que

\footnotetext{
XAMENA y RiERA, op. cit. (nota 5), p. 168.

42 ADM (Archivo Diocesano de Mallorca), Seminario, Hacienda, citado por Rosselló Lliteras, op. cit. (nota 3, 1988), p. 80 .

43 Este era el estado en que se hallaba el Seminario en 1710: "En el Seminari de Sant Pere, en el present, se troben quinze seminaristas ço es quatre que menten el dit Seminari y onze convictors, qui se mantenen de son propi y axi be que se trovaven anomenats per el Molt Ilustre Capitol para ohir los comptes y per los negocis del dit Seminari”. ACM, Actas Capitulares, 1643, fol. 178.

44 Mateu Mairata, G.: Obispos de Mallorca, Palma, Moll, 1985, p. 377.

45 ADM, Liber Communis, 1714-1716, f. 12.

46 Rotger Capllonch, op. cit. (nota 2), pág. 39.

47 BBM, Fondo del Convento de San Francisco, leg. 6, s/f.
} 
hallaban a la hora de cobrar las aportaciones a las que estaban obligadas algunas de las parroquias económicamente más poderosas. Y también, por la fragilidad de su autoridad episcopal, especialmente después de que el Cabildo hubiese gozado de tanto poder durante los años de la Guerra de Sucesión ${ }^{48}$. De hecho, destaca el caso del obispo Juan Fernández Zapata (1722-1729) como ejemplo ilustrativo de esta situación. Llegado a Mallorca en 1722, Zapata se había propuesto limpiar la Diócesis de los vicios imperantes en el clero y acabar con los desórdenes que todavía perduraban de los años de guerra ${ }^{49}$. Y entre sus objetivos estuvo el de conseguir definitivamente un Seminario adecuado para la formación del clero. Para tal fin, Zapata destinó gran número de limosnas para continuar las obras del edificio $\mathrm{y}$, al mismo tiempo, trazó un nuevo proyecto para ampliar el Seminario. Su forzoso traslado a la Diócesis de León en 1729 después de sumergirse en violentas disputas con los belicosos canónigos de la Catedral, volvió a frustrar una vez más el proyecto ${ }^{50}$.

Finalmente, estaba la cuestión de la Sapiencia. Por diversas circunstancias, aquel colegio había sabido sobrevivir más de un siglo con sus puertas abiertas y con colegiales residiendo allí, gozando de una situación aparentemente más estable que la que presentaba el nuevo Seminario. Su autonomía y sistema de autogobierno, con el Ayuntamiento de Palma y los obispos como simples patronos y supervisores, permitía al rector de turno ejercer un papel mucho más activo en la administración del centro ${ }^{51}$. De modo que, mientras el Seminario caía lentamente en una situación agónica, el colegio de la Sapiencia continuaba vigoroso, con visitadores enviados por sus copatronos que año tras año velaban por la supervivencia del centro y la buena administración de sus rentas ${ }^{52}$. De hecho, había quien pensaba que la Sapiencia funcionaba más como un Seminario que el propio edificio. A finales del siglo XVIII, un obispo recogió las opiniones que pervivían en Mallorca desde hacía muchos años y que evidencian esto:

Que más bien merece esta comunidad [la Sapiencia] el nombre de Seminario eclesiástico que el mismo Seminario Conciliar, y que la razón es clara; porque en el Seminario entran algunos convictores ricos e ilustres, y todos niños, cuyo talento, aplicación, espíritu y vocación apenas se puede conjeturar; y en el colegio entran ya menores, todos pobres y probados ${ }^{53}$.

48 La Guerra de Sucesión privó a Mallorca de obispo durante algunos años (1708-1711). Aunque es cierto que se habían dado sedes vacantes todavía más largas, las circunstancias que atravesaba la isla llevaron al Cabildo a ejercer con mayor ahínco el poder religioso de la Diócesis, pero valiéndose siempre de la figura del vicario general sede vacante para mantener la estabilidad y la tradición. Asimismo, cuando el obispo Estérripa asumió la mitra mallorquina, la victoria de las tropas borbónicas hizo al obispo arroparse en los canónigos, temeroso de sufrir el mismo destino que su antecesor, el obispo Portilla. Por lo tanto, durante las dos primeras décadas del siglo XVIII, los canónigos asumieron un poder vigoroso, y se enfrentaron con tesón a los obispos de aquella época. Pérez Martínez, L.: Resumen histórico de la Diócesis de Mallorca, Palma, Imp. SS. Corazones, 1959 , p. 41.

49 Furió i Sastre, A.: Episcopologio de la Santa Iglesia de Mallorca, Palma, imp. Juan Guasp, 1852, p. 475.

50 XAMENA y RierA, op. cit. (nota 5), p. 169.

51 AMP (Archivo Municipal de Palma), Actas Municipales, AH 2099/1, s/f.

52 Durante el siglo XVIII, muchos colegiales de la Sapiencia llegaron lejos en su carrera eclesiástica. En 1773, parece ser que "había habido 45 curas párrocos, 100 vicarios de cura de almas, 13 domeros de la Santa Iglesia [Catedral], 3 priores del santo Hospital General, dos colegiales de Nuestra Sra. Santísima de Lluc, dos vicerrectores de este Seminario conciliar de San Pedro, 40 catedráticos de Teología, Filosofía y Gramática, 9 opositores de canonicato, 6 canónigos de la Santa Iglesia [Catedral], 1 abad cisterciense". ADM, Fondo del Colegio de la Sapiencia, L.S/2.2.1, s/f.

53 BBM, Fondo del Convento de San Francisco, leg. 6, s/f. 
A partir de los años sesenta del siglo XVIII, comenzó a vivirse un proceso de cambio que no se redujo a la diócesis mallorquina. La subida al trono de Carlos III conllevó un fortalecimiento del poder de los obispos y el inicio de una profunda reforma de la Iglesia española, en la que, como no podía ser de otro modo, los seminarios cobraron un papel relevante ${ }^{54}$. Primeramente, esta nueva generación de obispos españoles, teniendo presentes algunas excepciones, se propuso limpiar sus respectivas diócesis de vicios y excesos heredados de épocas pasadas, elevando a su vez la calidad de la enseñanza del clero ${ }^{55}$. Los ambiciosos proyectos universitarios promulgados por el ministro Pablo de Olavide abrieron el camino para una profunda reforma educativa ${ }^{56}$. Asimismo, distintos prelados se tomaron como un reto personal renovar los seminarios y adecuarlos de una vez por todas a los principios propugnados por el Concilio de Trento. Así que, imponiéndose a los tradicionales obstáculos que se dejaban notar en la mayoría de diócesis -oposición del Cabildo, problemas para la dotación económica del edificio, o confrontaciones con colegios mayores-, se pusieron manos a la obra.

Una de las circunstancias que mayor influencia tuvo en las reformas educativas propugnadas por Carlos III, fue la expulsión de los jesuitas en 1767. Las presiones ejercidas por distintos ministros alrededor del trono se tradujeron en una orquestada campaña de desprestigio jesuítico que terminó con la tan famosa expulsión. La confiscación de todos los edificios pertenecientes a la Compañía, otorgaba a la Corona nuevas infraestructuras que podían ser destinadas a fines académicos. En Mallorca, por ejemplo, el famoso colegio de Montesión quedó agregado a la Universidad Luliana ${ }^{57}$.

La reforma sobre los seminarios tuvo una doble vía. Por un lado, se pretendía dotar a aquellas diócesis que aún no contaban con seminario, de uno adecuado a los ambiciosos proyectos ilustrados. En este sentido, destaca por ejemplo la construcción del Seminario conciliar de Ciudad Rodrigo, que quedó bajo la supervisión del obispo de aquel momento, Cayetano Antonio Cuadrillero (1763-1777) ${ }^{58}$. Por otro lado, se ambicionaba también remodelar los seminarios ya existentes, ampliando sus infraestructuras y reformando sus constituciones ${ }^{59}$. Seminarios como el de San Fulgencio de Murcia experimentaron importantes reformas ${ }^{60}$. Asimismo, el Seminario de San Antón, en Badajoz, cobró tal importancia en los años setenta del siglo XVIII, que puede considerarse "el único centro con rango oficial en la vida cultural de la ciudad de Badajoz"61.

54 SÁnchez-Blanco, F.: El absolutismo y las Luces en el reinado de Carlos III, Madrid, Marcial Pons, 2002, pp. 59 y ss.

55 Martín Hernández, F.: “La formación del clero en los siglos XVII y XVIII”, en García-VillosLadA, R. (dir.): Historia de la Iglesia en España, Madrid, Biblioteca de Autores Cristianos, 1984, pp. 557 y ss.

56 Véase Fernández SAnz, A: "La reforma universitaria del ilustrado Pablo de Olavide", Anales del Seminario de Historia de la Filosofía, extra 1 (1996), pp. 327-345.

57 Ramis Barceló, R.: "En torno a la supresión del connotativo 'Luliana' de la denominación històrica de la Universidad de Mallorca”, Memòries de la Reial Acadèmia Mallorquina d'Estudis Genealògics, Heràldics $i$ Històrics, 21 (2010), p. 109.

58 García SÁnchez, J.: Apuntes históricos del Seminario Conciliar de San Cayetano de Ciudad Rodrigo, Gijón, Universidad de Oviedo, 2009, p. 35.

59 Mas Galván, op. cit. (nota 21, 2004), p. 169.

60 Mas Galván, C.: "Jansenismo y regalismo en el Seminario de San Fulgencio de Murcia”, Anales de la Universidad de Alicante. Historia Moderna, 2 (1982), pp. 259-290.

${ }_{61}$ Sarmiento Pérez, J.: “Órdenes en la Diócesis de Badajoz (1800-1835)”, Norba, 18 (2005), p. 204. 
Por supuesto, el Seminario de Mallorca no fue ajeno a las grandes reformas que se abrían paso durante la década de los años sesenta del siglo XVIII. Un nuevo obispo se decidía a actuar para lo que pretendía ser un Seminario totalmente renovado. Francisco Garrido de la Vega (1763-1772) llegaba a la diócesis de Mallorca con cierto recelo y, al mismo tiempo, mentalizado en extirpar excesos ya demasiado enquistados en el clero isleño ${ }^{62}$. Consciente de que la isla vivía una inestabilidad social y religiosa que no terminaba de solucionarse, y que afectaba de lleno a los miembros del clero, el prelado inició su pontificado con gran prudencia. Por ejemplo, convocó a todos los beneficiados de la capital y les hizo realizar unos ejercicios espirituales "en los que los mejores teólogos y moralistas alternaban en la predicación, edificando sobre todo la modestia y compostura del prelado"63. Asimismo, colocó en algunas parroquias a sacerdotes, siempre sin privilegiar ninguna de las opiniones en discordia, que en este caso recordemos que eran principalmente el lulismo y el tomismo.

Y en lo que al Seminario de San Pedro se refiere, retomó el proyecto de sus antecesores en la mitra y programó una ambiciosa reforma y ampliación del edificio ${ }^{64}$. Gracias a los esfuerzos del prelado, las obras pudieron seguir adelante, consiguiendo "un cuadro perfecto todo de sillería, diestramente repartido en su oficina y departamentos, situado inmediato a la Universidad, capaz de 50 seminaristas, cada uno en habitación separada" ${ }^{65}$. Si en 1746, el Seminario sólo daba cabida a veintinueve seminaristas, el proyecto de Garrido había conseguido elevar su número casi al doble. Además, el prelado intentó solventar las eternas carencias económicas que arrastraba el Seminario. En efecto, sobre el Seminario pesaba una enorme deuda, fruto de tantos años con problemas a la hora de verse financiado. Parece ser que, en 1772, y según constataba el Ayuntamiento de Palma, tenía una deuda de 1.300 libras $^{66}$. De modo que el obispo, "viendo que la fábrica del seminario era reducida, e incómoda, trató de ampliarla expendiendo por sí solo 300 pesos" ${ }^{67}$. Pero lo cierto es que la remodelación del Seminario no era suficiente, y el prudente Garrido no se atrevió a ir demasiado lejos.

Como ocurría con otros seminarios peninsulares, el de San Pedro seguía sin contar con un cuerpo de maestros propio y continuaba funcionando como una residencia. La ambición perseguida por los obispos de aislar a sus seminaristas de influencias externas, era entonces imposible de cumplir. Todo lo contrario, los seminaristas "han ido hasta ahora a los conventos a estudiar, con la distracción y peligros que se dejan ver, siendo imposible destinar al rector o vicerrector para que los acompañe a uno acá y a otro allá" ${ }^{68}$. La discordia entre doctrinas que se respiraba en la Universidad, parecía hacerse ya muy palpable dentro del Seminario y la confrontación entre lulistas y tomistas estaba llegando a un punto insalvable. De hecho, hacia 1772, el rector registró distintos sucesos que alteraban la vida diaria en el edificio, especialmente en lo que se refiere a peleas entre seminaristas. Tenemos el caso, por ejemplo, de Antonio Danús de doce años. Mientras memorizaba unos ejercicios en su habitación, otro

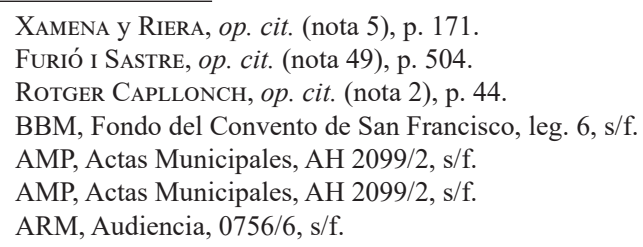


seminarista lulista entró y le hizo besar una estampa de Ramón Llull "con violencia de modo que le hizo llorar"69.

Fue precisamente en estas circunstancias, con la isla sometida a estas discordias religiosas, cuando se prepararon las grandes reformas del Seminario de San Pedro. En 1772, un obispo ambicionó conseguir lo que todos sus antecesores no habían conseguido.

\section{El gran proyecto del obispo Juan Díaz de la Guerra}

Juan Díaz de la Guerra llegaba a Mallorca en septiembre de 1772 directamente desde Roma $^{70}$. Hombre inteligente, ambicioso y trabajador, era a la vez altivo, de carácter nervioso y lo más importante, estaba desencantado con el destino que le habían asignado $^{71}$. Para cuando tomó posesión de la mitra, la isla se hallaba violentamente dividida. Lulistas y antilulistas disputaban en todos los estamentos, y el mundo académico mallorquín se hallaba seriamente alterado ${ }^{72}$. Mientras las filas tomistas se hallaban más fortalecidas que nunca y lanzaban todas sus armas para boicotear las enseñanzas de Ramón Llull y desterrarlas de la Universidad, el profesorado devoto del Mártir empezaba a perder las fuerzas y a sentirse impotente. Por lo mismo, las discordias estudiantiles parecían aumentar, y dentro del Seminario la tensión entre los seminaristas estaba a la orden del día ${ }^{73}$.

Para alguien como Díaz de la Guerra, que por un lado no soportaba ningún tipo de alteración o desorden que pudiese afectar a la Diócesis, y que por otro se declaraba un fervoroso tomista desde su infancia, estaba claro que debía intervenir en las disputas lulianas heredadas. Y lo cierto es que, durante sus cinco años como obispo de Mallorca, el prelado programó un ambicioso plan, que pretendía desterrar las doctrinas del Beato del mundo académico mallorquín y, al mismo tiempo, elevar la instrucción del clero ${ }^{74}$.

En primer lugar, Díaz de la Guerra puso sus ojos en el colegio de la Sapiencia. Frente a la autoridad que podía ejercer sobre el Seminario, se hallaba ahora ante un colegio que había gozado de gran autonomía, y que contaba con la protección de las

69 BBM, Fondo del Convento de San Francisco, leg. 5, f. 19 v.

70 Vid. García Pérez, F. J.: "La persecución del lulismo en la Catedral de Mallorca durante el episcopado de Juan Díaz de la Guerra (1772-1777)”, Hispania Sacra, 66 extra II (2014), pp. 397-419.

71 Para conocer un retrato psicológico del obispo Juan Díaz de la Guerra y si situación especialmente durante los meses anteriores a su partida a Mallorca, véase GARcía PÉREz, F. J.: Devoción y violencia en Mallorca durante el siglo XVIII. La represión antiluliana durante el pontificado del obispo Juan Díaz de la Guerra (1772-1777), Tesis doctoral inédita, Granada, Universidad de Granada, pp. 158 y ss.

72 Ramis BARCELÓ, op. cit. (nota 57, 2010), p. 110.

73 El rector del Seminario hizo llegar un informe al obispo en el que le relataba las disputas que se vivían diariamente dentro del edificio, especialmente desde que los colegiales habían ingresado en él. En primer lugar, si creemos en las palabras del rector, se daba la circunstancia de que "que querían los unos forzar [a] los otros a que rezasen y diesen el culto, que no querían, a dicho Lulio". Pero, además, Díaz de la Guerra también se declaraba enterado de continuos enfrentamientos entre seminaristas como consecuencia de dichas estampas, "con que [lulistas] insultaban a otros seminaristas, a más de ser dichas estampas de perjuicio". Fuese porque el obispo necesitaba argumentos para desterrar todo vestigio del Seminario, no podemos descartar que las distintas opiniones, tomista y lulista, despertaban enfrentamientos entre los seminaristas. Biblioteca Pública de Mallorca (BPM), ms. 1125, fol. 4.

74 García Pérez, F. J.: "La represión antiluliana del obispo Díaz de la Guerra en Andratx", Memòries de la Reial Acadèmia Mallorquina d'Estudis Genealògics, Heràldics i Històrics, 24 (2014), p. 90. 
élites mallorquinas ${ }^{75}$. Además, su defensa exacerbada del lulismo doctrinal seguramente creaba enormes recelos en el prelado. Así que, a mediados de 1773, escribió en secreto a Carlos III. Aprovechándose de un momento realmente oportuno, pues el monarca estaba enfrascado en una profunda reforma que afectaba a los colegios mayores ${ }^{76}$, Díaz de la Guerra le vendió la imagen de un colegio decrépito y sin rentas suficientes para mantenerse. Y para solucionar esta situación, le proponía unificar las dos comunidades dentro del Seminario, trasladando a los colegiales allí y clausurando la Sapiencia, pero manteniendo sus constituciones intactas ${ }^{77}$.

Aunque Díaz de la Guerra presentó un informe detallado de las ventajas que suponía la unión de ambos centros, lo cierto es que a la larga beneficiaban siempre al Seminario. En primer lugar, la Sapiencia había constituido un freno natural para el florecimiento del Seminario de San Pedro. Su antigüedad le había labrado ya una reputación, y, por lo tanto, algunos jóvenes aún preferían optar a una beca en la Sapiencia, y no en el Seminario ${ }^{78}$. Clausurando la Sapiencia, decía el obispo, "se lograría un seminario de un número competente de seminaristas escogidos, [...] y se lograría establecer aquella virtud y letras que S.M. desea en ejecución del Concilio"79. Mientras se cerraba el centenario colegio, el Seminario ampliaba su plantilla de integrantes. En segundo lugar, eliminando la Sapiencia, Díaz de la Guerra acababa con uno de los principales focos de lulismo académico de Mallorca. No olvidemos que el colegio contribuía enormemente a fortalecer el estudio de lulismo en la Universidad. Según sus constituciones, los colegiales estaban obligados a instruirse en el Ars Magna luliana en su último año de residencia ${ }^{80}$. De modo que si lo que el obispo pretendía era fortalecer el tomismo, obligatoriamente tenía que acabar con dicha institución.

Finalmente, en octubre de 1773, Carlos III se declaraba enterado de las ventajas que suponía la anexión de la Sapiencia al Seminario de San Pedro y ordenaba al prelado "decretar y ejecutar la unión [...] con sus rentas, derechos y obligaciones, y a formar las Constituciones que entendieseis más arregladas y oportunas para el mejor gobierno del Seminario en lo sucesivo" $"$. Además, el rey otorgaba plenos poderes al obispo para ejecutar el ambicioso plan de unión de centros. Este fue el primer paso. Una vez se expulsó a los colegiales de la Sapiencia y se les instaló en el Seminario, el rector les obligó a despojarse de todos los símbolos que los caracterizaban como hijos de la Sapiencia, "sin conservarles el hábito de colegiales, la observancia de sus constituciones, ni la obediencia que tenían jurada a su legítimo rector" ${ }^{82}$. Solo podían continuar asistiendo a sus clases en la Universidad, aunque Díaz de la Guerra tenía ya sus propios planes con respecto a eso.

75 García Pérez, F. J.: "Represión académica en la Mallorca del siglo XVIII. El obispo Juan Díaz de la Guerra y la clausura del colegio de la Sapiencia en 1773", Chronica Nova, 41 (2015), p. 119.

76 El momento no podía ser más oportuno. Desde 1771, Carlos III había puesto sus miras en el universo de los colegios mayores, planificando reformas destinadas a purgar viejos vicios e innovar sus estructuras y funcionamiento. El objetivo de este intervencionismo anticolegial, que en esencia era un capítulo más dentro de la reforma universitaria de su ministro Pablo de Olavide, pretendía "cambiar el tipo de persona que ocupaba las becas [...] y adecuar el plan de estudios a las necesidades del tiempo". CARABIAS Torres, A. M.: "Evolución histórica del colegio mayor. Del siglo XIV al XXI", REDEX. Revista de Educación de Extremadura, 5 (2013), p. 71.

77 García PÉREZ, op. cit. (nota 74, 2015), p. 201.

78 Ramis Barceló, op. cit. (nota 32, 2014), p. 259.

79 Rosselló Lliteras, op. cit. (nota 28, 1988), p. 216.

80 Trias Mercant, op. cit. (nota 18), pág. 171.

81 BBM, Fondo del Convento de San Francisco, leg. 6, s/f.

82 BBM, Fondo del Convento de San Francisco, leg. 6, s/f. 
Una vez el obispo finiquitó el asunto de la Sapiencia, se propuso continuar elevando la situación del Seminario. El paso siguiente fue acabar con las discordias que poblaban el edificio desde hacía tantos años. Y una vez más, se aprovechó de un incidente aparentemente aislado para conseguir sus objetivos. El 16 de abril de 1774, un seminarista llamado Antonio Campins dañó un cuadro del Beato en mitad de una clase de Gramática, después de meses sometido al acoso que le propinaban algunos universitarios por no venerar a Ramón Llull ${ }^{83}$. A la mañana siguiente, el claustro proluliano tenía ya preparado un severo castigo para aquel seminarista. Con la clase cerrada bajo llave, y en presencia del resto de estudiantes y del mismo vicerrector, el profesor de Gramática "levantó la sotana al expresado Campins, quien estaba acuestas desatacado, y le zurraba" ${ }^{84}$. Cuando Díaz de la Guerra tuvo noticia del incidente, se enfureció hasta tal punto que abrió una sumaria criminal contra los profesores implicados en la zurra ${ }^{85}$. El maestro de Gramática terminó expulsado de la Universidad y desterrado a su parroquia de Porreras. El vicerrector, que había dado la orden para el castigo, ingresó en la Casa de la Misión hasta nuevo aviso ${ }^{86}$. Y en cuanto al seminarista Campins, se le confirió "una beca [...] y sin ser pobre"87.

A continuación, llegaron las grandes reformas al Seminario de San Pedro. Se trataba de un proyecto que, en palabras de Díaz de la Guerra, perseguía "que nuestros seminaristas tengan las devociones solidas que deberán enseñar a nuestros pueblos" $"$. Por lo tanto, lo que el prelado pretendía era revisar la situación interna de los seminaristas, desde los libros que leían, sus enseñanzas, sus horarios, hasta sus devociones privadas. Aunque la historiografía tradicional mallorquina no ha querido ver más allá de una persecución del culto religioso a Ramón Llull dentro del Seminario, las medidas de Díaz de la Guerra abarcaban mucho más. De hecho, el prelado estaba seguro de que estaba haciendo un bien por sus seminaristas, y por el estado de la Diócesis en general. Además, esta especie de cesarismo sin fisuras no fue ninguna excepción en la España de Carlos III. Con sus reformas, Díaz de la Guerra reproducía las ansias típicas del despotismo ilustrado de subyugar todos los ámbitos de la Iglesia de Mallorca ${ }^{89}$. Como bien dice el historiador Amengual i Batle, pese a que el Seminario de San Pedro no nació de las presiones ejercidas por los ilustrados reformadores, no por ello se libró del "control dels dèspotes il·lustrats, no sempre zelosos de l'Evangeli, i mai revestits d'una missió eclesial" "90.

Primeramente, Díaz de la Guerra programó una persecución iconográfica dentro del Seminario, ordenando que se requisase toda estatua, talla o cuadro del Beato existente en el edificio ${ }^{91}$. El rector se vio obligado a retirar los cuadros y estatuas de Llull que reposaban en la capilla, con la excusa de que "los colegiales que estudiaban la Doctrina de Lulio molestaban a los de otras escuelas a que las adorasen, y [...]

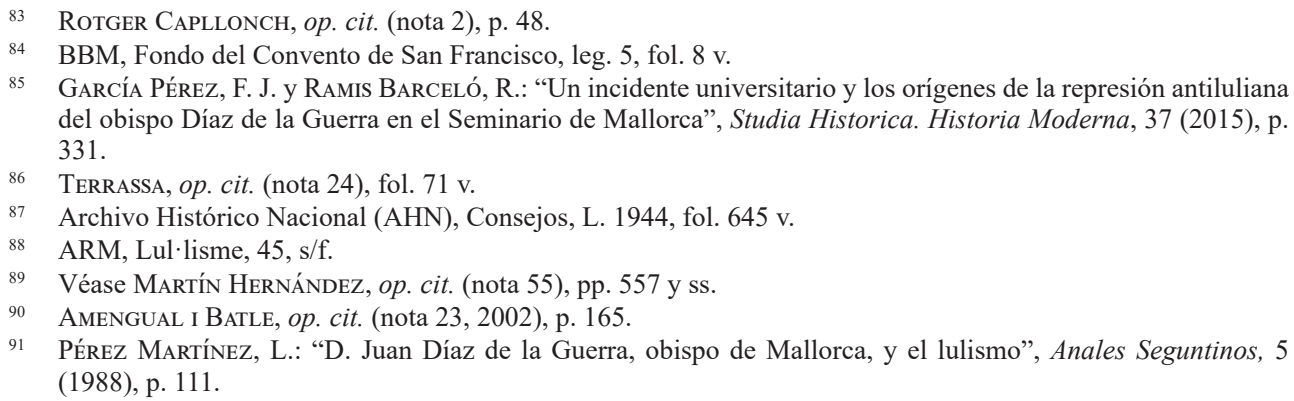


afligían con amenazas y malos tratamientos"92. Ya en su poder, el día 15 de enero de 1775 fueron trasladados definitivamente al Palacio Episcopal, donde quedaron custodiados por orden del obispo ${ }^{93}$. Igualmente, fueron requisadas "cuantas estampas y estatuas de barro, o de otra materia, [que] se hallen en dicho Nuestro Seminario introducidas por algunos seminaristas, y fijadas en sus aposentos" ${ }^{\prime 4}$.

Una vez limpió el Seminario de cualquier influencia devocional e iconográfica relacionada con Ramón Llull, Díaz de la Guerra "había expedido una orden a todos los colegas del Seminario que debían estudiar la Doctrina de Santo Tomas"95 dentro del mismo edificio. La idea era dotarlo de un cuerpo de maestros interno, simpatizantes todos ellos de la doctrina de Santo Tomás ${ }^{96}$. Por eso mismo, una vez hicieron su entrada los profesores, el obispo decretó que todos los seminaristas tenían prohibida su asistencia a la Universidad Literaria ${ }^{97}$. Ahora su formación íntegra iba a quedar reducida al interior del Seminario conciliar, precisamente "para evitar el motivo de la distracción, que puede ocasionar a la juventud, que se cría para el servicio de la Iglesia, la precisión de acudir a los Generales" $" 98$.

El escándalo que se desató en Palma fue mayúsculo. La salida de los seminaristas de la Universidad fue vista como un "fomento de partidos y facciones, el perjuicio y la transgresión de los estudios de los colegas y de Vuestra Real Universidad" 99 . Sin embargo, Díaz de la Guerra estaba convencido de las ventajas que suponía su plan. Él mismo defendía que "no puede dar [el Seminario] mejor doctrina que la letra de Santo Thomas, [...] siendo así que con el Santo Doctor no puede competir alguno en la aceptación de la Iglesia Universal"100. Lo cierto, sin embargo, es que los obstáculos fueron demasiados para el obispo. Sus intentos de dotar al Seminario de un cuerpo de maestros se vieron sistemáticamente frustrados por una oposición frontal.

Mientras los profesores residían ya en el Seminario, los colegiales de la Sapiencia se fugaron la noche del 22 de septiembre de 1775 por "el modo irregular con que han sido tratados en el propio seminario conciliar", y se negaron a regresar hasta que se respetasen sus condiciones ${ }^{101}$. Asimismo, el Ayuntamiento de Palma y el Cabildo denunciaron los procederes del obispo a la Real Audiencia. Por ejemplo, los canónigos se quejaban de la falta de espacio que ahora se deducía de la unión de comunidades, pues por "el aumento de colegas de que no es capaz el edificio, [...] se ven precisados a dormir dos y tres en un cuarto, cuando las Constituciones del Seminario

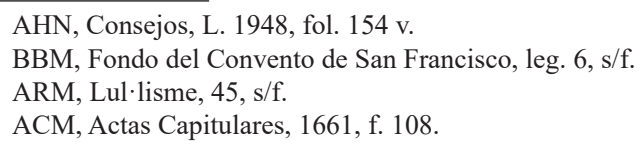

AHN, Consejos, L. 1948, fol. 154 v.

BBM, Fondo del Convento de San Francisco, leg. 6, s/f.

ARM, Lul·lisme, 45, s/f.

ACM, Actas Capitulares, 1661, f. 108.

96 Díaz de la Guerra procedió a elegir como maestros "al Sr. Dr. Jaime Obrador, catedrático de dogmática y disciplina eclesiástica, al Sr. Dr. Don Guillermo Ramón, profesor de filosofía, y al Dr. don Juan Barceló, vicerector del mismo seminario, maestro de gramática y retórica”. RotGER CAPLLONCH, op. cit. (nota 1), p. 56.

97 La prohibición a los seminaristas de asistir a la Universidad debe entenderse desde la perspectiva del propio obispo. Díaz de la Guerra, un declarado tomista, consideraba las doctrinas de Santo Tomás como las más adecuadas para la formación del clero. Contrariamente, los seminaristas podían elegir libremente la opción filosófica y teológica entre las cuatro que allí se impartían -tomismo, lulismo, escotismo y suarismo-, si bien es cierto que, a partir de 1767 , se dio por finalizada la enseñanza del suarismo y la mayoría de sus estudiantes terminaron pasándose al escotismo. En definitiva, lo realmente importante es que, impartiendo lecciones internas en el Seminario, Díaz de la Guerra podía controlar también el programa educativo de sus seminaristas. Véase RAmis BARceló, op. cit. (nota 35, 2010), pp. 237-263.

98 ARM, Audiencia, 0756/6, fol. 7 v.

99 BBM, Fondo del Convento de San Francisco, leg. 6, s/f.

100 ARM, Audiencia, AA 0756/006, s/f.

101 AMP, Actas Municipales, AH 2100/2, s/f. 
prohíben aún el entrar el uno en el del otro"102. Y, por si esto no fuera suficiente, el profesorado universitario intentó boicotear los planes del obispo dentro del Seminario, especialmente increpando a los maestros internos a abandonar el edificio.

En febrero de 1777, y con la isla sometida más que nunca a ese ambiente de discordias religiosas y doctrinales que arrastraba desde principios del siglo XVIII, Carlos III ordenó a Díaz de la Guerra que abandonase la Diócesis, nombrado ahora obispo de Sigüenza ${ }^{103}$. La partida del obispo terminó de frustrar las grandes reformas proyectadas sobre el Seminario de San Pedro. De hecho, los años siguientes se sumió en un período de decadencia y olvido.

Con la Diócesis sin obispo, el nuevo vicario general sede vacante, el canónigo Nicolás Villalonga acordó junto al resto del Cabildo, reinvertir las medidas que Díaz de la Guerra había implantado. Con el claustro exigiendo el retorno de los seminaristas a la Universidad, lo primero que hizo Villalonga fue expulsar del Seminario a los profesores de tomismo ${ }^{104}$. A continuación, removió la campaña antiluliana que inundaba todas las estancias del edificio, mandando que "se reintegre [...] la dicha observada costumbre en dicho Seminario de rezar el padre nuestro al Beato Raimundo Lulio en la misma conformidad que se observaba antes de la prohibición"105. Y en cuanto a los colegiales, hizo todo lo posible para conseguir nuevamente la separación de ambas comunidades, volviendo a abrir el colegio de la Sapiencia, aunque esto no ocurrió hasta 1783.

Tuvieron que pasar muchos años para volver a observar nuevas reformas en el Seminario de San Pedro. Durante el resto del siglo XVIII, la experiencia de Díaz de la Guerra hizo que el Cabildo catedralicio, ya desencantado desde la propia fundación del mismo, se desentendiese todavía más del proyecto. Asimismo, los obispos inmediatamente posteriores tenían asuntos más urgentes que tratar, y dejaron el Seminario tal y como lo habían encontrado.

Hubo que esperar al siglo XIX para observar cambios. En 1830, Fernando VII ordenó que se clausurara la Universidad Literaria de Mallorca y se convirtiera en un seminario conciliar dependiente del de Cervera ${ }^{106}$. De modo que el obispo de aquel momento se halló con dos seminarios y, al mismo tiempo, con una oportunidad inmejorable para intervenir en la formación del clero. Nuevamente, se incluyó un cuerpo de profesores internos, precisamente lo que Díaz de la Guerra se había propuesto en $1776^{107}$. Y, además, el prelado organizó un ambicioso plan de estudios que permitiera a los seminaristas más aventajados poder ampliar su formación en otros seminarios, e incluso en Roma ${ }^{108}$. Por tanto, lo que había tardado más de un siglo en conseguirse, solo fue realmente posible cuando una de las infraestructuras académicas más importantes, la mismísima Universidad de Mallorca, fue eliminada. En cuanto a la Sapiencia, perduró durante muchos años más, conviviendo con el Seminario, y convirtiéndose, en muchos sentidos, en la razón de ser del mundo académico mallorquín.

\footnotetext{
BBM, Fondo del Convento de San Francisco, leg. 6, s/f.

AHN, Consejos, L. 6867, ex. 6, s/f.

Rotger Capllonch, op. cit. (nota 2), p. 56.

ARM, Lul·lisme, 62, s/f.

106 Vid. Fullana Puigserver, P.: "La Reial i Pontifícia Universitat Literària de Mallorca: entorn del fet de la supressió (1829-1835)", Afers: fulls de recerca i pensament, 10 (1995), pp. 117-128.

107 Rosselló Lliteras, op. cit. (nota 28, 1988), p. 240.

108 RAMis BARCELó, op. cit. (nota 35, 2010), pág. 257.
} 


\section{Conclusiones}

Los inicios del Seminario de Mallorca no fueron nada sencillos. Aunque el Concilio de Trento estableció la necesidad de dotar a las diócesis de seminarios conciliares que elevasen el nivel de instrucción del clero, hubo que esperar siglos para poder ver ese objetivo cumplido. Como se ha visto, los obstáculos eran demasiados para los sucesivos obispos, y no solo en Mallorca. La fundación de un seminario implicaba la inversión de un capital que, muchas veces, no se contemplaba. En muchas diócesis, fueron precisamente los cabildos catedralicios algunos de sus mayores frenos a la hora de implantar seminarios, precisamente porque se negaban a verse privados de parte de sus rentas. Al mismo tiempo, no todos los obispos contemplaron del mismo modo tan titánica tarea. De hecho, incluso después de Trento, fueron muchos los que continuaron delegando esa misión para un momento más oportuno. Y así, a inicios del siglo XVIII, muchas diócesis del sur de Europa, en especial, no contaban todavía con seminarios conciliares, y algunos de los que existían ya, no cumplían con la idea que Trento había diseñado.

La isla de Mallorca es solo un ejemplo más de esta situación. Prueba de ello está en que hubo que esperar hasta 1700, en un momento en el que el obispo Pedro de Alagón, únicamente sobreponiéndose y enfrentándose a la infinidad de obstáculos que pervivían, pudo finalmente convertir ese proyecto en una realidad. Curiosamente, la erección del Seminario de San Pedro no atajó las dificultades. Todo lo contrario, durante toda la centuria, el nuevo seminario vivió en un vaivén de avances y retrocesos, sometido siempre a la posible imagen de un definitivo cierre. Un ejemplo está en que, muy pocos años después de que el Seminario abriese sus puertas, el estallido de la Guerra de Sucesión, el destierro de su sucesor, el obispo Portilla, y la larga sede vacante, frustraron ya la culminación del gran proyecto que se estaba gestando. El Cabildo catedralicio, ahora con el poder religioso en sus manos, se negaba a seguir contribuyendo en aquel seminario. Las parroquias más ricas ponían mil excusas para no aportar su pequeña porción. Y, además, ya existían otras instituciones que llevaban años supliendo medianamente la inexistencia de un seminario. Hubo que esperar al final de la guerra y a la llegada del obispo Fernández Zapata para comenzar a vislumbrar algunos cambios.

Como se viene diciendo, durante la primera mitad del siglo XVIII, el Seminario bailó entre algunos avances y el olvido. El edificio se hallaba en un estado decadente, no se conseguía dotar nuevas becas que ampliasen el número de seminaristas, el rector tenía serios problemas para administrar la economía interior del Seminario, y los excesos inherentes en el clero del Setecientos continuaban todavía muy enquistados. Además, el hecho de que el Seminario funcionase más como una residencia, ocasionaba no pocos problemas, especialmente porque los seminaristas estaban en contacto diario con las confrontaciones doctrinales que se vivían en la Universidad luliana y literaria. En efecto, la disparidad de opiniones era una realidad, especialmente entre el lulismo y el tomismo. Como los seminaristas tenían plena libertad para elegir la opinión que quisieran, se veían seriamente afectados por las disputas universitarias, y las trasladaban al propio Seminario. Así, se fue desarrollando paulatinamente una violencia disfrazada que estaba reducida a los aposentos de los seminaristas o a las zonas comunes, pero que muchas veces quedaba alejada de los ojos del rector y del vicerrector. 
Únicamente pudo comprobarse un verdadero intento de cambio dentro del Seminario durante el último tercio del siglo XVIII. Uno de los grandes proyectos en la órbita de la denominada Ilustración en España, fue, precisamente, una reforma profunda y contundente del clero católico. De hecho, muchos obispos se tomaron como un reto personal la mejora de sus respectivos seminarios y, en otras ocasiones, la erección de seminarios conciliares a imagen del legado dejado por Trento. Y, como cabía esperar, las grandes reformas ilustradas de Carlos III no fueron ajenas a Mallorca. De hecho, en los años sesenta, el obispo Francisco Garrido de la Vega se sobrepuso a las disputas heredadas de sus antecesores en la mitra, y programó un ambicioso plan para reformar el Seminario. Se trataba, principalmente, de una ampliación del edificio para dar cabida a un número mayor de seminaristas, $\mathrm{y}$, al mismo tiempo, reformar aquellas zonas existentes que se hallaban en un estado decadente. Por lo tanto, esta reforma fue limitada. Garrido no se atrevía todavía a implantar cambios como los que estaban viviendo otros seminarios conciliares de la Península, especialmente en lo referente a la introducción de un cuerpo de maestros residente en el Seminario, que aislara a los seminaristas de las influencias externas, y especialmente de las disputas doctrinales de la Universidad.

En estas circunstancias, hace su aparición uno de los obispos que mayor empeño puso en concluir un Seminario acorde a los intereses de la monarquía carolina, y en consonancia con las disposiciones tridentinas. El gran proyecto de Díaz de la Guerra fue, sin lugar a dudas, muy convulso para la realidad del clero mallorquín. Por primera vez, un prelado se sobreponía a los tradicionales obstáculos y programaba grandes avances. El cierre del colegio de la Sapiencia en 1773, pese a las justificaciones del obispo, únicamente benefició al Seminario, que ahora gozaba de una ampliación de los seminaristas y de sus rentas. La purga de la iconografía y devoción lulianas en las estancias del Seminario pretendía, principalmente, atajar las discordias doctrinales y la disparidad de opiniones. Y finalmente, la introducción de un cuerpo de maestros perseguía aislar a los seminaristas de las influencias externas y favorecer las enseñanzas de Santo Tomás, que Díaz de la Guerra consideraba las más acertadas para la instrucción del clero. Aunque es cierto que generaron gran desconcierto entre la población mallorquina, y el descontento general, se trata de unas reformas que se estaban implantando en otras diócesis españolas con mayor éxito.

Ciertamente, el siglo XVIII no terminó de ser un momento apropiado para la fundación de un seminario en Mallorca. Mientras otros territorios españoles tuvieron mayor suerte a la hora de implantarlos, en la isla existían demasiados obstáculos, especialmente si los introducía un obispo foráneo que se enfrentaba a las instituciones de poder, y especialmente, al Cabildo de la Catedral. Esto lo demuestra el hecho de que hubo que esperar al siglo XIX, en un momento precisamente en que las instituciones tradicionales destinadas a la enseñanza del clero, como la Universidad Literaria, sucumbieron por orden regia. Solo entonces, y ante la necesidad, los obispos se vieron obligados a privilegiar verdaderamente un seminario adecuado. 